\title{
GEOMETRIC FACTOR IN SEASONAL VARIATIONS OF DAILY AVERAGE VALUES OF THE GEOMAGNETIC INDEX Dst
}

\author{
G.A. Makarov \\ Yu.G. Shafer Institute of Cosmophysical Research \\ and Aeronomy SB RAS, \\ Yakutsk, Russia, gmakarov@ikfia.ysn.ru
}

\begin{abstract}
The work uses data on the geomagnetic index Dst for the period 1966-2015. Under quiet conditions, the occurrence of seasonal variations of the daily average Dst index depends on geometric factors of the interaction between the solar wind and the magnetosphere; and under disturbed conditions, on the development of a partial ring current in the magnetosphere. At large negative values of the $D s t$ index, there is no seasonal variation in it. The imperfection of the network of Dst stations is assumed to lead to the formation of annual variation in $D s t$. The formation of a semiannual varia-
\end{abstract}

tion is associated with the movement of the plasma sheet relative to the plane of the geomagnetic equator during the annual rotation of Earth around the Sun. Based on the data on semiannual variations in the number of days $n(D s t)$, the critical daily average value of the geomagnetic index Dst is determined, starting from which we can speak of disturbed days: $D s t \leq-24 \mathrm{nT}$.

Keywords: geomagnetic index $D s t$, semiannual variation of magnetic activity.

\section{EXPERIMENTAL MATERIAL}

An interesting feature of seasonal variations in geomagnetic activity is their semiannual variation with maxima near equinoctial periods. The semiannual variation occurs in all latitudinal zones and is common to all known geomagnetic indices. Study of its causes began over a century ago, but the question about mechanisms of its occurrence is still unanswered. All the proposed mechanisms of the semiannual variation in geomagnetic activity are usually divided into three classes: axial [Cortie, 1912]; equinoctial [Bartels, 1932]; Russell-McPherron mechanism [Russell, McPherron, 1973]. The combined effect of different mechanisms seems to be more probable [Murayama, 1974; Simon, Legrand, 1989; Cliver et al., 2000; Svalgaard et al., 2002; Danilov, Makarov, 2006; Petrukovich, Zakharov, 2007]; what is important in this regard is to clarify the contribution of mechanisms of each class.

In addition to the semiannual variation, geomagnetic activity has an annual variation whose maximum phase in different indices is observed in different periods and is determined by the latitude and geometry of the network of stations providing data to calculate a given index.

Geomagnetic activity is a significant factor in solarterrestrial processes. Solar-terrestrial relations and space weather effects are often studied by statistical methods using daily average values of terrestrial, interplanetary, and solar parameters. Nonetheless, at daily averaging of terrestrial parameters different phases of geomagnetic storms may overlap, the storm parameters (phase, intensity, duration, etc.) are largely smoothed over, and the results differ from the results obtained from processing of geomagnetic storms separately by phases or with respect to a reference moment in storm development. Thus, it is important to analyze variations in daily average values of the low-latitude geomagnetic index Dst. This paper focuses on seasonal variations of two characteristics of the Dst index - the frequency of occurrence and magnitude.
This paper uses data on the Dst index [Sugiura, Kamei, 1991] from the World Data Center for Geomagnetism, Kyoto, Japan, for 1966-2015 [http://wdc.kugi.kyotou.ac.jp]. Figure 1 shows the distribution of the number $n$ of the daily average Dst index by magnitude in 1966-2015. A total of 18262 days has been analyzed. The number of days with $D s t>0$ is $\sim 17.66 \%$; with $D s t \approx 0, \sim 2.34 \%$; and with Dst $<0, \sim 80.0 \%$.

\section{SEASONAL DISTRIBUTION OF THE NUMBER OF DAYS}

Figure 2 depicts seasonal distributions of the number of days $n$ with positive and negative daily average Dst. The number of days with positive Dst is seen to be maximum during solstices, with the summer maximum far exceeding the winter one; while the number of days with negative $D s t$ is maximum during equinoxes.

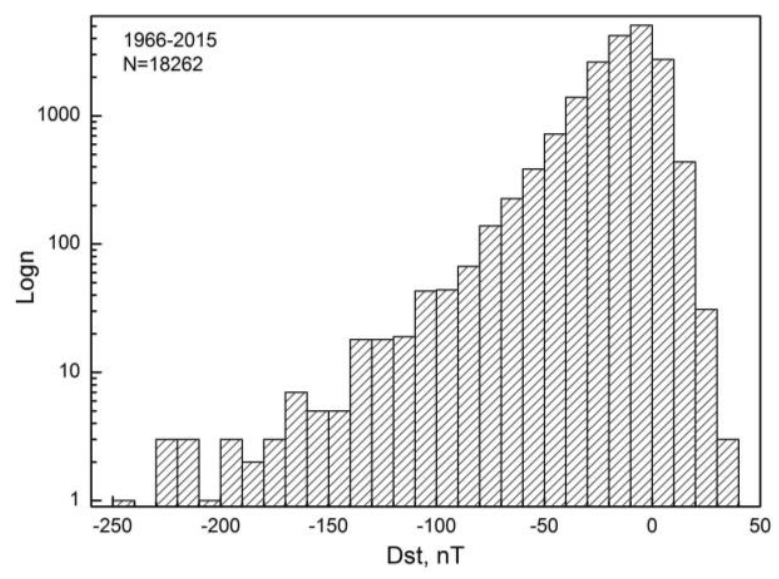

Figure 1. Distribution of the daily average Dst index by magnitude on a logarithmic scale, $N$ is the total number of days in 1966-2015 


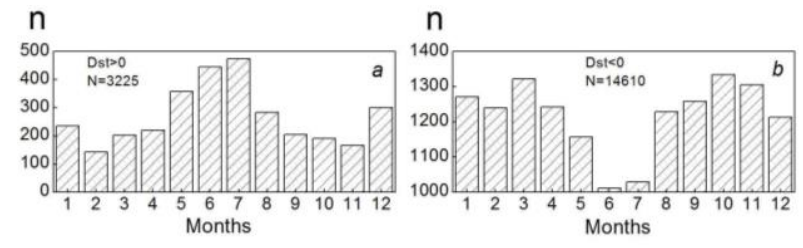

Figure 2. Seasonal distributions of the number of days $n$ with positive $(a)$ and negative $(b)$ daily average $D s t ; N$ is the number of days in a sample

The harmonic analysis of these series shows that seasonal variations in the number of days are well fitted by the first two harmonics. If $n(D s t>0)$, the amplitude of the first harmonic $R_{1}=102.6$, the phase of maximum $\varphi_{1}$ occurs on June 11, the amplitude of the second harmonic $R_{2}=94.1$, the phase of maximum $\varphi_{2}$ is around June 9 (December); whereas in the case of $n(D s t<0), R_{1}=99.0$, $\varphi_{1}$ is around December $4, R_{2}=91.7, \varphi_{2}$ is around March 14 (September). Amplitudes of these harmonics are expressed in days. As can be seen, in both cases amplitudes of the first and second harmonics are approximately equal, and the phases of the corresponding harmonics are opposite, and for negative Dst the phases of the maxima of the second harmonic are close to the periods of equinoxes ( March 21 and $\sim$ September 22$)$ and to the periods when the heliolatitude of Earth reaches its highest values (March 5-7 and September 6-8).

To study the seasonal dynamics of $n$ depending on the magnetic disturbance level in more detail, distributions of $n$ have been obtained for individual ranges of the daily average $D s t$ index (Figure 3 ).

It is clearly seen that the distributions of $n$ vary in ranges: at a low disturbance level (Figure $3, a, b$ ) the histograms are similar to the histogram of $n(D s t>0)$ (Figure 2,a); and at higher levels, to the histogram of $n(D s t<0)$ (Figure 2,b). Results of the harmonic analysis of the $n$ distributions for these samples are presented in Figure 4 and in Table.

Figure 4 shows that amplitudes of the first and the second harmonics of seasonal distributions of the number of days $n$ with increasing absolute $\langle D s t\rangle$ vary in a complicated manner: at a low disturbance level, $R_{1}$ and $R_{2}$ increase, then, as the disturbances level goes up, begin to decrease; and at a high disturbance level they do not change.

The ratio of amplitudes of the harmonics to $n$ allows us to take into account the number of days $n$ in individual ranges of $D s t$ values. It is seen (see Table) that the ratio $R_{1} / n$ is practically independent of the disturbance level, whereas the ratio $R_{2} / n$ at a low disturbance level with increasing geomagnetic activity first decreases and then, starting from the fourth group $(\langle D s t\rangle$ less than $-20 \mathrm{nT})$, steadily increases. The ratio $R_{2} / R_{1}$, starting from the fourth group of activity, with increasing magnetic disturbance level also exhibits an increase, with the amplitude of the second harmonic of seasonal distributions of $n$ at a high disturbance level significantly exceeding the amplitude of the first harmonic.

The phase of maximum of the first harmonic at a low disturbance level is observed during the summer solstice, but during moderate to severe disturbances it changes by $180^{\circ} \mathrm{C}$ and takes place in the winter solstice. The seventh point is a spike (small statistics); the sixth and eighth points are observed at the beginning of February — the end of January, i.e. they fall into the regular pattern and occur near the winter solstice.

Behavior of the phase of the second harmonic has well-defined features: at a low disturbance level (the first three points when $D s t>-20 \mathrm{nT}$ ) seasonal variation maxima are observed in the solstice; whereas at medium and high disturbance levels, at equinox; the average value for five samples $\left\langle\varphi_{2}\right\rangle=3.73$ months, which corresponds to March 22 (September). This phase transition characterizes the critical level of the daily average disturbance, i.e. from $-20 \mathrm{nT}>$ Dst $>-30 \mathrm{nT}$, we can speak of a substantial development of the ring current.

The analysis of histograms of the number of days with $\langle D s t\rangle$ from -20 to $-26 \mathrm{nT}$ has pinned down this critical level: $\langle D s t\rangle \approx-24 \mathrm{nT}$. Thus, the semiannual variation in the number of days $n$ with maxima during equinoxes for daily average $D s t$ begins from $\langle D s t>\approx-24 \mathrm{nT}$. When working with daily average data, we can take this value as threshold in assessing the disturbance level: the days when $\langle D s t\rangle$ is less than $-24 \mathrm{nT}$ can be regarded as disturbed.

\section{SEASONAL DISTRIBUTION OF THE Dst INDEX}

Consider seasonal variations in the Dst index. Figure 5 shows seasonal variations in daily average Dst for the entire period (a) and for the days with $<D s t><0 \mathrm{nT}(b)$. In both cases, semiannual waves are clearly seen. According to the calculations, the amplitude of the first harmonic of the seasonal variation in $\langle D s t\rangle$ for all days is $2.68 \mathrm{nT}$, the phase of minimum values falls on December 17, while in the case of Dst $<0 R_{1}=1.17 \mathrm{nT}$, and the phase of minimum falls on January 4; the amplitude of the second harmonic of the seasonal variation for all days is $4.82 \mathrm{nT}$, the phase of minimum falls on March 18 (September); whereas in the case of $D s t<0 \quad R_{2}=4.03 \mathrm{nT}$, and the phase of minimum occurs on March 22 (September). In both cases, the first harmonic suggests that the strongest disturbance takes place during the winter solstice, while the second harmonic is observed during the vernal and fall equinoxes. And in both cases, the amplitude of the second harmonic exceeds that of the first harmonic: 1.8 times for all days, 3.4 times for $D s t<0$.

Figure 6 shows seasonal variations in the Dst index for individual ranges of daily average values. We can see that the curves for different ranges of daily average $D s t$ behave differently. In the first five ranges (Figure 6, $a-e$ ), the minimum values of $\langle D s t\rangle$ are observed during equinoxes; in the next two (Figure $6, f, g$ ), they are closer to the periods of solstices; and in the last range (Figure $6, h$ ) there is no noticeable semiannual wave in the seasonal variation of the Dst index. Such dynamics of the Dst index is likely to reflect the effect of various factors: geometrical factors of the interaction between the solar wind and the magnetosphere under quiet conditions, and partial ring current in the magnetosphere as the disturbance level increases. 

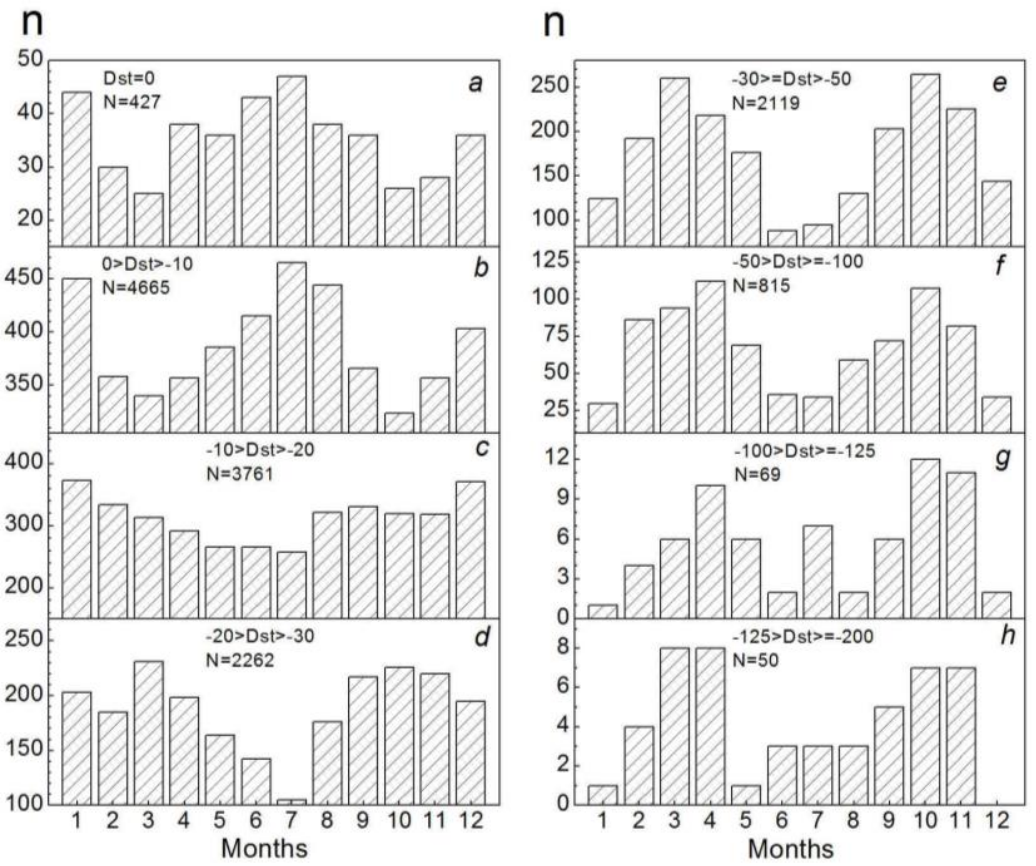

Figure 3. Seasonal distribution of the number of days $n$ for individual ranges of daily average $D s t$; each panel $(a-h)$ presents $D s t$ ranges in $\mathrm{nT}$ and the number of days $N$ in a respective sample

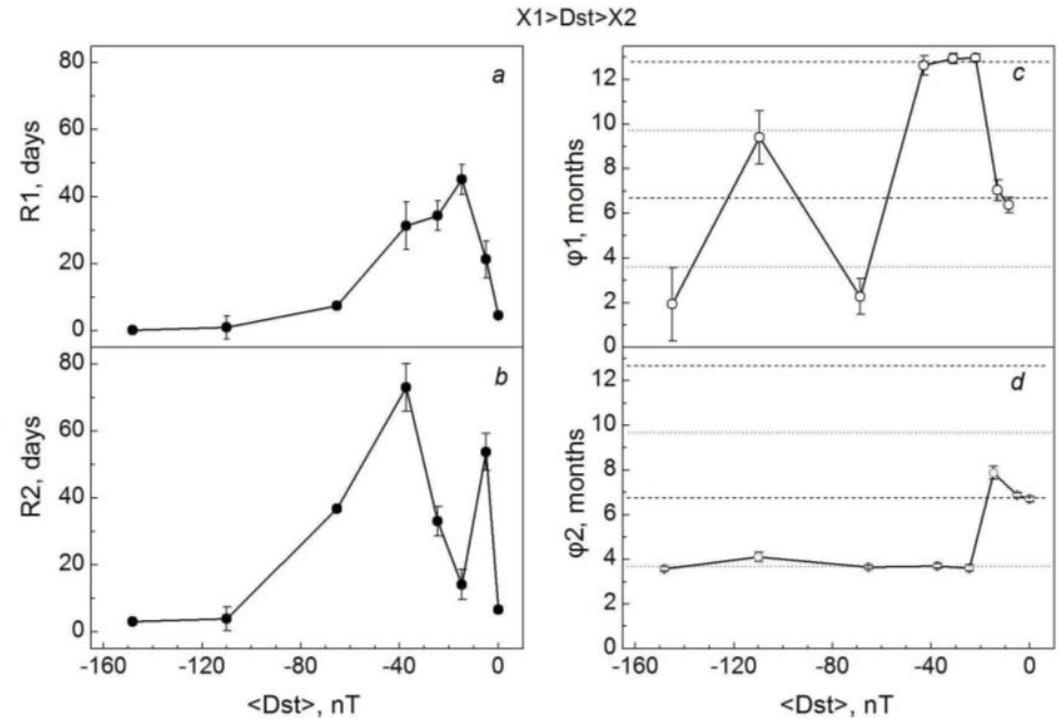

Figure 4. Amplitudes $\left(R_{1}\right.$ and $\left.R_{2}\right)$ and phases $\left(\varphi_{1}\right.$ and $\left.\varphi_{2}\right)$ of the first and second harmonics of seasonal distributions of $n$ as function of average $\langle D s t\rangle$ in a given range of values. In the right part, dashed lines indicate solstice periods; dotted lines, equinoctial periods; for $\varphi_{1}$ and $\varphi_{2}$, ordinal numbers of months are given. Standard deviations of averages are exhibited

Average $\left\langle D s t>\right.$ and relative amplitudes of the first $\left(R_{1} / n\right)$ and second $\left(R_{2} / n\right)$ harmonics of seasonal variations in $n$ in individual ranges of daily average $D s t$ (magnetic disturbance levels)

\begin{tabular}{|l|l|c|c|c|l|}
\hline No. & Disturbance level, nT & $\langle D s t>, \mathrm{nT}$ & $R_{1} / n$ & $R_{2} / n$ & $R_{2} / R_{1}$ \\
\hline 1 & $D s t=0$ & 0.00 & 0.0105 & 0.0156 & 1.4778 \\
\hline 2 & $0>D s t>-10$ & -5.02 & 0.0046 & 0.0115 & 2.5342 \\
\hline 3 & $-10>D s t>-20$ & -14.69 & 0.0120 & 0.0038 & 0.3130 \\
\hline 4 & $-20>D s t>-30$ & -24.59 & 0.0152 & 0.0146 & 0.9638 \\
\hline 5 & $-30 \geq D s t>-50$ & -37.41 & 0.0148 & 0.0345 & 2.3350 \\
\hline 6 & $-50>D s t \geq-100$ & -65.41 & 0.0091 & 0.0450 & 4.9474 \\
\hline 7 & $-100>D s t \geq-125$ & -110.00 & 0.0136 & 0.0571 & 4.1915 \\
\hline 8 & $-125>D s t \geq-200$ & -148.20 & 0.0028 & 0.0608 & 21.7143 \\
\hline
\end{tabular}



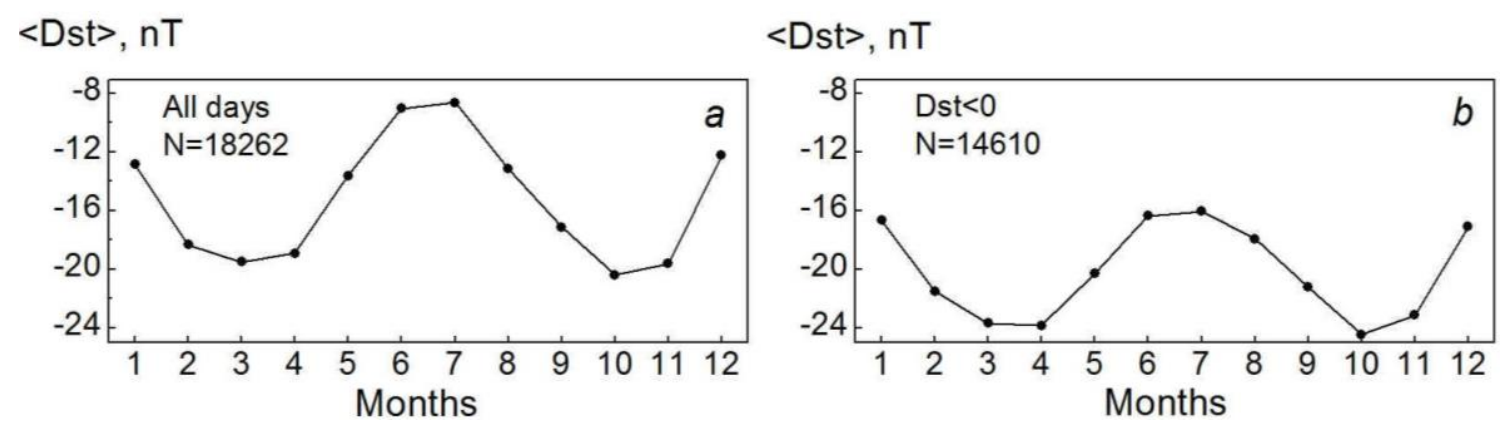

Figure 5. Seasonal variations in the daily average $D s t$ index for all days $(a)$ and for $D s t<0(b) ; N$ is the number of days in the sample

The development of the ring current during geomagnetic storms, with its inclination in the latitudinal direction and shift to the dawn and dusk sides are examined by Liu et al. [2019], using SuperMAG data. Yet, since ranges of the seasonal variations in the Dst index are small and do not exceed $2 \%$ of the average $\langle D s t\rangle$ in each range of values (see Table), this paper discusses the Dst variations shown in Figure 5. Note that the patterns found from the data presented in Figures 3 and 6 have been tested for reproducibility by expanding two times the ranges of daily average $D s t$, and the results received are similar to those considered.

\section{DISCUSSION}

As we can see, seasonal variations in the number of days $n$ and daily average $D s t$ feature annual and semiannual variations. The annual and semiannual variations in $n$ have comparable amplitudes. In quiet periods and at a low disturbance level, the annual $n$ variations have maxima in the summer solstice, but with increasing disturbance level the maxima occur around the winter solstice. The summer maximum of $n$ can be explained by the fact that during quiet periods in the absence of the ring current the Dst index probably results from the impact of magnetopause currents and the residual Sq-field (e.g., [Chen, 2004]).

As the disturbance level increases, the occurrence of $D s t$ variations begins to be affected by the geometry of the network of stations whose data is used to calculate the index. Earlier studies [Danilov, Makarov, 1984, 1992] have shown that the annual variation in Dst is formed due to the nonuniform distribution of the network of stations: three of four stations are in the Northern Hemisphere. The predominance of northern stations leads to the annual variation in Dst with the greatest depression during the winter solstice (Figure 5). Indeed, if we assume that the partial ring current is, like the plasma sheet, in the plane oriented toward the solar plasma flow (Figure 7), in winter months the nightside magnetosphere, where the partial ring current flows, is projected to the Northern Hemisphere. As a result, lowlatitude stations in the Northern Hemisphere record a greater depression of the geomagnetic field than stations in the Southern Hemisphere.

The influence of the geometry of the network of stations on the occurrence of annual and diurnal Dst variations has also been studied in works of other authors. For example, Mayaud [1978] supposed that the diurnal variation in the Dst index is probably due to the asymmetric part of the ring current, which is not averaged because of the nonuniform longitudinal distribution of stations. Mursula, Karinen [2005] have shown that due to seasonal variation in the magnetic field in stations and owing to the incorrect treatment of the quiet time curve when constructing the Dst index there occurs a «non-storm component» of Dst variations, which is almost half the semiannual variation. Hakkinen et al. [2003] have shown that at different stations mean levels of the Dst index differ by $\sim 10 \mathrm{nT}$ due to the fact that the stations have different basic levels of Dst; to eliminate the secular variation a new method has been proposed which can correct the seasonal variation in the Dst index by $\sim 3 \mathrm{nT}$. In addition, to eliminate the differences between the hemispheres during the winter and summer solstices, the network is proposed to be complemented by two stations in the Southern Hemisphere.

Examine the behavior of the maximum phase of the second harmonic in the distribution of the number of days $\varphi_{2}(n)$ with increasing magnetic disturbance level (see Figure $4, d$ ). During weak disturbances, the seasonal variation maxima are observed in solstices; during moderate and severe disturbances, in equinoxes. Daily average $\langle D s t\rangle \approx-24 \mathrm{nT}$ is defined as threshold to assess the daily disturbance level. Starting from this value, we can speak of a substantial development of the ring current in the magnetosphere. According to the classification of geomagnetic storms [Loewe, Prolss, 1997; Gonzalez et al., 1994], weak storms develop when the hourly average $D s t \leq-30 \mathrm{nT}$. Note that this classification uses hourly average $D s t$, whereas in this paper the daily disturbance level is estimated from daily average Dst; hence there is no discrepancy.

Observation of maxima of the semiannual variation in $n$ and minimum Dst exactly during equinoxes of March 22 (September) argues for the equinoctial mechanism behind this variation [Bartels, 1932]. According to our assumption, the semiannual variation occurs for the following reason [Danilov, Makarov, 2006]. As is known, solar wind particles enter the magnetotail and due to the electric drift move toward Earth. As the particles approach Earth, their energy increases. The energetic particle flux is concentrated near the neutral line of the magnetotail, forming a relatively thin plasma sheet of energetic plasma particles. During equinoctial periods when the Earth axis is transverse to the Earth-Sun 

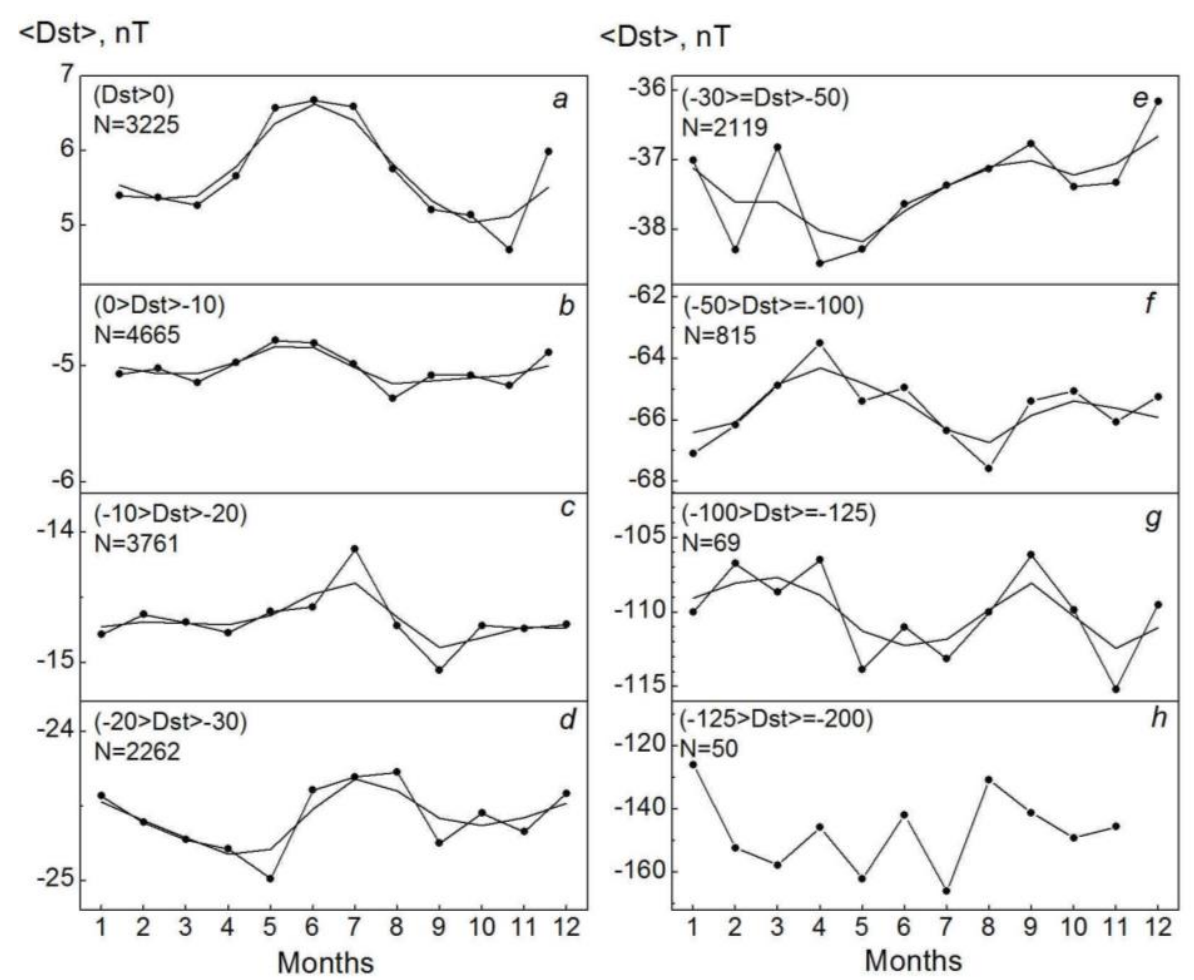

Figure 6. Seasonal variations in daily average $D s t$ for individual ranges of values: broken lines with dots indicate experimental data; smooth curves, smoothed values. Each panel shows ranges of $D s t$ values in nT and the number of days in a sample $N$

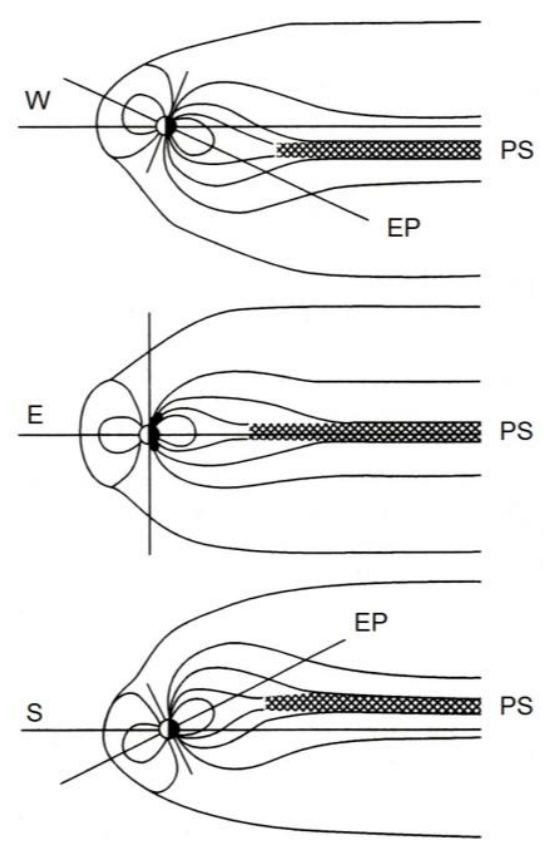

Figure 7. Schematic layout of the plasma sheet (PS) of the magnetosphere relative to the equatorial plane (EP) in winter $(\mathrm{W})$, in equinoxes (E), and summer (S) [Danilov, Makarov, 2006]

line, the plasma sheet of the magnetotail is directed to the geomagnetic equator (see Figure 7). In those periods, the earthward particle flux velocity is perpendicular to field lines of the dipole magnetic field, and the probability of particle influx into the magnetosphere is the greatest. In summer and winter periods, when the Earth axis deviates from the Earth-Sun line toward the Sun and from the Sun, the plasma sheet shifts with respect to the geomagnetic equator plane and the particle flux velocity decreases. This reduces the probability of particle influx into the magnetosphere and hence decreases the partial ring current intensity. So, we can qualitatively describe the formation of the semiannual Dst variation with minimum values during equinoxes. Using $K$ indices for mid-latitude stations as an example, Danilov, Makarov [2006] have shown that the semiannual magnetic activity variations associated with variations in the angle of impact of the solar wind on Earth's magnetosphere make up $60 \%$, the other $40 \%$ are linked to changes in Earth's heliolatitude. In this paper, this ratio manifests itself in the seasonal distribution of the number of days $n$ with negative daily average $D s t$ (see Figure 2).

An explanation in terms of geometry (Figure 7), similar to the above, has been proposed by Mayaud [1978]; the author attributes origin of the semiannual Dst variation to the Malin-Isikara effect: during annual revolution of Earth around the Sun the ring and tail currents shift to the north in winter (Northern Hemisphere) and to the south in summer due to compression of the magnetosphere by the solar wind [Malin, Isikara, 1976]. The Malin-Isikara effect was also used to explain the annual and diurnal Dst variations [Mayaud, 1978; Cliver et al., 2001; Takalo, Mursula, 2001]. The difference between the schemes proposed in [Danilov, Makarov, 2006] and [Malin, Isikara, 1976] is that the former takes into account the shift of the plasma sheet as a source of ring current particles relative to the geomagnetic equator, whereas the latter considers the annual variation of the middle latitude of the ring current. 
The assumptions about variation in the location of the partial ring current relative to the geomagnetic equator plane [Danilov, Makarov, 1984, 1992; Malin, Isikara, 1976] are confirmed by the results received in [Liu et al., 2019], in which SuperMAG data for 2000-2014 has been analyzed and the ring current location in the magnetic latitude during 67 intense geomagnetic storms has been identified.

It appears that spatial and temporal effects of the ring and partial ring currents can be found from the results of studies of $S Y M$ and $A S Y$ indices, which are determined from data acquired by the eleven low- and mid-latitude geomagnetic stations. We will carry out such studies in the future.

This paper does not estimate the contribution of the mechanism [Russell, McPherron, 1973] to seasonal Dst variations since no account is taken of the magnetic field direction in interplanetary sectors. Since daily average Dst and a large amount of data spanning 50 years are used, we can assume that in a first approximation effects of IMF sectors as well as its northward and southward components are compensated.

Thus, the occurrence of seasonal variations in daily average values of the Dst geomagnetic index under quiet and moderately disturbed conditions (to $D s t>-50 \mathrm{nT}$ ) is affected by geometric factors of interaction between the solar wind and the magnetosphere, and as the disturbance level goes up the effect of the partial ring current in the magnetosphere increases. At large negative values, the $D s t$ index has no seasonal variation.

\section{CONCLUSION}

It is assumed that the occurrence of the annual Dst variation with minima during the winter solstice is caused by the nonuniform distribution of the network of stations whose data is used to calculate Dst: three of four stations are located in the Northern Hemisphere. If the partial ring current is, like the plasma sheet, in the plane oriented toward the solar plasma flow, the nightside magnetosphere, where the partial ring current flows, is projected to the Northern Hemisphere in winter, and low-latitude stations in this hemisphere record a greater depression of the geomagnetic field than stations in the Southern Hemisphere.

An explanation of the occurrence of semi-annual variations in the number of days with negative and positive daily average values of $D s t$ and in the $D s t$ index has been put forward. It is based on consideration of the movement of the plasma sheet relative to the geomagnetic equator plane during annual revolution of Earth around the Sun, which corresponds to the change in the probability of particle influx into the magnetosphere and subsequent variations in the partial ring current intensity. The highest probability of particle influx into the magnetosphere takes place during equinoxes; the lowest, during solstices.

From data on semiannual variations in the number of days $n(D s t)$, the critical daily average value of $D s t$, starting with which the day can be regarded as disturbed: $D s t \leq-24 \mathrm{nT}$, has been found.

\section{REFERENCES}

Bartels J. Terrestrial magnetic activity and its relations to solar phenomena. Terrestrial Magnetism and Atmospheric Electricity. 1932, vol. 37, iss. 1, pp. 1-52.

Chen H.-F. Analysis of the diurnal and semiannual variations of Dst index at different activity levels. J. Geophys. Res. 2004, vol. 109, A03212. DOI: 10.1029/2003JA009981.

Cliver E.W., Kamide Y., Ling A.G. Mountains versus valleys: Semiannual variation of geomagnetic activity. J. Geophys. Res. 2000, vol. 105, iss. A2, pp. 2413-2424. DOI: 10.1029/ 1999JA900439.

Cliver E.W., Kamide Y., Ling A.G., Yokoyama N. Semiannual variation of the geomagnetic Dst index: Evidence for a dominant nonstorm component. J. Geophys. Res. 2001, vol. 106, iss. A10, pp. 21297-21304. DOI: 10.1029/ 2000JA000358.

Cortie A.L. Sunspots and terrestrial magnetic phenomena 1898-1911: The cause of the annual variation of magnetic disturbances. Mon. Not. Roy. Astron. Soc. 1912, vol. 73, pp. 52-60. DOI: $10.1093 / \mathrm{mnras} / 73.1 .52$.

Danilov A.A., Makarov G.A. Sector structure of IMF and ring current in magnetosphere. Fizicheskie protsessy $v$ okolozemnoi plazme [Physical processes in near-Earth plasma], Yakutsk, 1984, pp. 28-40. (In Russian).

Danilov A.A., Makarov G.A. On the effect of the distribution of geomagnetic observatories on diurnal and seasonal variations of the Dst-index. Magnitosfernye issledovaniya [Magnetospheric research], Moscow, 1992, no. 18, pp. 125-129. (In Russian).

Danilov A.A., Makarov G.A. Dependence of magnetic activity on the plasma sheet location relative to the geomagnetic equator. Geomagnetism and Aeronomy. 2006, vol. 46, iss. 2, pp. 159-165. DOI: 10.1134/S0016793206020046.

Gonzalez W.D., Joselin J.A., Kamide Y., Kroehl H.W., Rostoker G., Tsurutani B.T., Vasyliunas V.M. What is a geomagnetic storm? J. Geophys. Res. 1994, vol. 99, iss. A4, pp. 5771-5792. DOI: 10.1029/93JA02867.

Hakkinen L.V.T., Pulkkinen T.I., Pirjola R.J., Nevanlinna H., Tanskanen E.I., Turner N.E. Seasonal and diurnal variation of geomagnetic activity: Revised $D s t$ versus external drivers. $J$. Geophys. Res. 2003, vol. 108, iss. A2, 1060. DOI: 10.1029/ 2002JA009428.

Liu B.J., Zhang X.X, He F. Tilt of the ring current during the main phases of intense geomagnetic storms. Science China. Technological Sciences. 2019, vol. 62, iss. 5, pp. 820-828. DOI: $10.1007 / \mathrm{s} 11431-018-9344-5$.

Loewe C.A., Prolss G.W. Classification and mean behavior of magnetic storms. J. Geophys. Res. 1997, vol. 102, iss. A7, pp. 14209-14213. DOI: 10.1029/96JA04020/

Malin S.R.C., Isikara A.M. Annual variation of the geomagnetic field. Geophys. J. R. Astron. Soc. 1976, vol. 47, pp. 445-457. DOI: 10.1111/j.1365-246X.1976.tb07096.x.

Mayaud P.N. The annual and daily variations of the Dst index. Geophys. J. R. Astron. Soc. 1978, vol. 55, pp. 193-201. DOI: 10.1111/j.1365-246X.1978.tb04757.x.

Murayama T. Origin of the semiannual variation of geomagnetic $K_{\mathrm{p}}$ indices. J. Geophys. Res. 1974, vol. 79, iss. 1, pp. 297-300. DOI: 10.1029/JA079i001p00297.

Mursula K., Karinen A. Explaining and correcting the excessive semiannual variation in the Dst index. Geophys. Res. Lett. 2005, vol. 32, L14107. DOI: 10.1029/2005GL023132.

Petrukovich A.A., Zakharov M.Y. $a_{\mathrm{p}}$-index solar wind driving function and its semiannual variations. Ann. Geophys. 2007, vol. 25, iss. 7, pp. 1465-1469. DOI: 10.5194/angeo-251465-2007/

Russell C.T., McPherron R.L. Semiannual variation of geomagnetic activity. J. Geophys. Res. 1973, vol. 78, iss. 1, pp. 92-108. DOI: 10.1029/JA078i001p00092. 
Simon P.A., Legrand J.-P. Solar cycle and geomagnetic activity: A review for geophysicists. Part II: The solar sources of geomagnetic activity and their links with sunspot cycle activity. Ann. Geophys. 1989, vol. 7, iss. 6, pp. 579-594.

Sugiura M., Kamei T. Equatorial Dst index 1957-1986. IAGA Bull. 1991, no. 40, pp. 7-14.

Svalgaard L., Cliver E.W., Ling A.G. The semiannual variation of great geomagnetic storms. Geophys. Res. Lett. 2002, vol. 29, iss. 16, 1765. DOI: 10.1029/2001GL014145.

Takalo J., Mursula K. A model for the diurnal universal time variation of the Dst index. J. Geophys. Res. 2001, vol 106, iss. A6, pp. 10905-10921. DOI: 10.1029/2000JA000231.

URL: http://wdc.kugi.kyoto-u.ac.jp (accessed June 5, 2020).

How to cite this article

Makarov G.A. Geometric factor in seasonal variations of daily average values of the geomagnetic index Dst. Solar-Terrestrial Physics. 2020. Vol. 6. Iss. 4. P. 50-56. DOI: 10.12737/stp-64202008. 